\title{
Environmental regulations, innovation and firm performance: A revisit of the Porter hypothesis
}

Ramanathan, R., He, Q., Black, A., Ghobadian, A., Gallear, D.

Author post-print (accepted) deposited by Coventry University's Repository

Original citation \& hyperlink:

Ramanathan, R, He, Q, Black, A, Ghobadian, A \& Gallear, D 2016, 'Environmental regulations, innovation and firm performance: A revisit of the Porter hypothesis' Journal of Cleaner Production, vol (in press). DOI: 10.1016/j.jclepro.2016.08.116 https://dx.doi.org/10.1016/i.jclepro.2016.08.116

DOI $\quad 10.1016 / j . j c l e p r o .2016 .08 .116$

ISSN 0959-6526

ESSN $1879-1786$

Publisher: Elsevier

NOTICE: this is the author's version of a work that was accepted for publication in journal of cleaner production. Changes resulting from the publishing process, such as peer review, editing, corrections, structural formatting, and other quality control mechanisms may not be reflected in this document. Changes may have been made to this work since it was submitted for publication. A definitive version was subsequently published in journal of cleaner production, VOL in press (2016) DOI: 10.1016/j.jclepro.2016.08.116

(C) 2016, Elsevier. Licensed under the Creative Commons Attribution-

NonCommercial-NoDerivatives 4.0 International

http://creativecommons.org/licenses/by-nc-nd/4.0/

Copyright $(\subset$ and Moral Rights are retained by the author(s) and/ or other copyright owners. A copy can be downloaded for personal non-commercial research or study, without prior permission or charge. This item cannot be reproduced or quoted extensively from without first obtaining permission in writing from the copyright holder(s). The content must not be changed in any way or sold commercially in any format or medium without the formal permission of the copyright holders.

This document is the author's post-print version, incorporating any revisions agreed during the peer-review process. Some differences between the published version and this version may remain and you are advised to consult the published version if you wish to cite from it. 


\section{Accepted Manuscript}

Environmental regulations, innovation and firm performance: A revisit of the Porter hypothesis

Ram Ramanathan, Qile He, Andrew Black, Abby Ghobadian, David Gallear

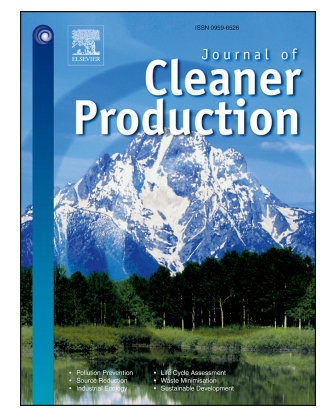

PII:

S0959-6526(16)31264-1

DOI:

10.1016/j.jclepro.2016.08.116

Reference: JCLP 7908

To appear in: Journal of Cleaner Production

Received Date: 4 February 2016

Revised Date: 27 July 2016

Accepted Date: 23 August 2016

Please cite this article as: Ramanathan R, He Q, Black A, Ghobadian A, Gallear D, Environmental regulations, innovation and firm performance: A revisit of the Porter hypothesis, Journal of Cleaner Production (2016), doi: 10.1016/j.jclepro.2016.08.116.

This is a PDF file of an unedited manuscript that has been accepted for publication. As a service to our customers we are providing this early version of the manuscript. The manuscript will undergo copyediting, typesetting, and review of the resulting proof before it is published in its final form. Please note that during the production process errors may be discovered which could affect the content, and all legal disclaimers that apply to the journal pertain. 


\title{
Environmental Regulations, Innovation and Firm Performance: A Revisit of the Porter Hypothesis
}

\author{
Ram Ramanathan ${ }^{\mathrm{a}}$, Qile He ${ }^{\mathrm{b}}$ * , Andrew Black ${ }^{\mathrm{c}}$, Abby Ghobadian ${ }^{\mathrm{d}}$, David Gallear ${ }^{\mathrm{e}}$ \\ a. University of Bedfordshire Business School, UK \\ (Ram.Ramanathan@beds.ac.uk) \\ b. Coventry Business School, Coventry University, UK \\ (qile.he@coventry.ac.uk) \\ c. Nottingham University Business School, UK \\ (agwblack@gmail.com) \\ d. Henley Business School, University of Reading, UK \\ (abby.ghobadian@henley.ac.uk) \\ e. Brunel Business School, Brunel University, UK \\ (David.Gallear@brunel.ac.uk)
}

* Corresponding author:

Dr Qile He, Coventry Business School, Coventry University, Priory Street, Coventry, CV1 5FB, United Kingdom. Email: qile.he@ coventry.ac.uk. Tel: +44 (0)24 77658846 


\title{
Environmental Regulations, Innovation and Firm Performance: A Revisit of the Porter Hypothesis
}

\begin{abstract}
This paper examines the relationships between environmental regulations, firms' innovation and private sustainability benefits using nine case studies of UK and Chinese firms. It aims to unravel the mechanisms by which a firm's environmental behaviour in improving its private benefits of sustainability is influenced by its relationship with the government, which primarily enacts regulations to maximise public sustainability benefits in the interests of society as a whole. The paper takes its cue from the Porter hypothesis to make some broad preliminary assumptions to inform the research design. A conceptual framework was developed through inductive case studies using template analysis. The results show that depending on firms' resources and capabilities, those that adopt a more dynamic approach to respond to environmental regulations innovatively and take a proactive approach to manage their environmental performance are generally better able to reap the private benefits of sustainability.
\end{abstract}

Keywords: Environmental regulations; Flexibility; Innovation; Public benefits of sustainability; Private benefits of sustainability; Porter hypothesis 


\section{Introduction}

Among various elements of corporate sustainable development (CSD), pollution prevention/control is arguably a facet where the government is attempting to influence firm behaviour and where the public and private benefits of sustainability overlap (Porter and van der Linde, 1995b). This is done by promulgating environmental regulations. Although there is a general consensus on the requirement for governmental legislation to regulate the environmental responsibilities of corporations, there is still debate on how best governments can formulate regulations and how best corporations can use the regulatory requirements to improve their own performance (Bi et al., 2014; Debnath, 2015; Ford et al., 2014; Majumdar and Marcus, 2001; Orlitzky et al., 2003; Porter and van der Linde, 1995a; Rubashkina et al., 2015; Tanaka, 2015; Zhao et al., 2015).

The primary aim of this paper is to examine how the public and private benefits of sustainability are influenced by two prominent actors: the government and private firms. Governments aim to improve public benefits of sustainability through regulation (for example in the form of reduced pollution) by requiring firms to adopt sustainable practices, while firms attempt to maximise private benefits (for example, in the form of reduced consumption of energy/raw material) that positively impacts their bottom line. Regulations are a common form of governance structure (Williamson, 1999). The impact of environmental regulations on the financial performance of firms is contentious. The traditional view, rooted in neoclassical economics, considers regulations as damaging to business, albeit socially desirable; more modern perspectives suggest that, if properly designed, regulations can in fact improve firms' business performance by inspiring and facilitating innovation (Porter and van der Linde, 1995a,1995b; Tello and Yoon, 2008). The ability of a firm to meet regulatory requirements and at the same time improve its overall performance is sometimes called a 'win-win' scenario or the Porter hypothesis (Porter, 1991). The Porter hypothesis is key to understanding how environmental regulation could simultaneously result in public and private benefit.

Recent insights from industrial ecology suggest that the design of regulations combined with environmental variables is crucial in determining their potential to create win-win scenarios (Costa and Ferrao, 2010; Costa et al., 2010). 'Flexible regulation' (also referred to as 'innovation friendly' and 'smart' regulation) is considered a crucial driver of a positive outcome for all stakeholders (Majumdar and Marcus, 2001; Partzsch, 2009). Others suggest that factors such as managerial attitude and the capacity of a firm to innovate are also important in determining the nature of the relationship between environmental regulations and business performance (Christmann, 2000; Iraldo et al., 2009; Lopez-Gamero et al., 2010). Empirical research examining these concepts is beginning to develop. A major gap is if and how regulation flexibility and firm innovativeness impacts on financial performance - a point addressed by this paper. This study builds on and extends the Porter hypothesis by offering a more comprehensive explication of the mechanisms representing the interplay between environmental regulations, innovation and financial performance of firms. More specifically, this paper develops a framework to evaluate the current design of environmental regulations. Moreover, inspired by the dynamic capabilities view (DCV) of the firm (Teece et al., 1997), the conceptual framework better articulates the differences in the ability of firms to respond to regulatory pressures dynamically and to innovate to achieve positive win-win outcomes leading to both public and private sustainability benefits. 
The conceptual framework is derived empirically from the case studies using an inductive logic (see also Eisenhardt and Graebner, 2007). Some broad a priori assumptions are first developed based on the Porter hypothesis. The intention is not to test these assumptions but to use them as guidelines to conduct case studies and as the starting point for advancing the Porter hypothesis. Nine case studies from the UK and China were conducted to gain deeper insights. Implications for policy makers responsible for environmental regulations, and for firms implementing and managing them, are discussed.

\section{Theoretical foundations}

\subsection{Environmental regulations: the Porter hypothesis}

Environmental regulations can play an important role in limiting the harmful effects of economic activity on the natural environment; however, they can also impose a significant cost on businesses (Blackman et al., 2010; Filbeck and Gorman, 2004; Gray and Shadbegian, 2003). The conventional wisdom prevalent throughout the 1970s and 80s was that while regulations might be desirable from a broader social perspective, the impact on business would be negative, as firms are forced to internalise environmental costs that had previously been ignored (e.g. Barbera and McConnell, 1990; Gollop and Roberts, 1983).

To rectify the seemingly paradoxical relationship between environmental regulation and firms' financial performance, a growing number of researchers have highlighted the argument of Porter (1991), who argued that environmental regulations, rather than uniformly penalising all firms, afford some firms the opportunity to become more competitive, consequently improving their financial performance. Porter developed his ideas further in two subsequent papers published with Claus van der Linde (Porter and van der Linde, 1995a, 1995b). They argued that regulations, if properly designed and with an appropriate level of flexibility, may induce cost-saving innovation exceeding compliance costs. The idea that environmental regulations can improve a firm's environmental and financial performance via their impact on innovation has become known as the Porter hypothesis or the win-win hypothesis (Ambec and Barla, 2006).

The Porter hypothesis has been tested in several studies but these tests have shown mixed results. Some studies concluded that environmental regulation leads to lower financial returns (Filbeck and Gorman, 2004), others detected a positive impact (Zhu et al., 2007), while others found no discernible relationship (Triebswetter and Hitchens, 2005). The picture is similar when the relationship between regulation and innovation was studied: inconclusive (Jaffe and Palmer, 1997; Sanchez and McKinley, 1998), positive impact (Brunnermeier and Cohen, 2003; Horbach, 2008) and negative impact (Walker et al., 2008).

Only a very few studies have sought to examine the relationship between these three constructs (regulations, innovation and performance) simultaneously (Eiadat et al., 2008; Lopez-Gamero et al., 2010; Montabon et al., 2007; Ramanathan et al., 2010; Triebswetter and Wackerbauer, 2008). Triebswetter and Wackerbauer (2008) found that environmental regulation did not improve performance, nor did it significantly harm it. They conclude that regulation is only one of the many drivers of innovation, and the effects of regulation-driven innovations on competitiveness are similar to those of innovations motivated by other pressures. Using data from firms in Jordan, Eiadat et al. (2008) investigated whether 
environmental innovation would mediate the relationship between regulations and economic performance. They found strong support for the Porter hypothesis. Black et al. (2010) investigated the moderating effect of innovation on the relationship between regulations and economic performance. They found that innovation positively moderates the relationship in the case of more flexible regulations but not in the case of less flexible regulations - hence hinting at the important role played by the design of regulations and the capability of the regulated (i.e. firms) to innovate.

A careful examination of the prior work suggests that a probable cause for the mixed findings is ignoring the two conditions that Porter and van der Linde explicitly identified as being necessary for the positive impact of environmental regulations on business performance. These are (1) sufficient regulation design flexibility (policy issue); and (2) the willingness of the regulated firms to respond 'dynamically' (firm issue). This paper attempts to fill this gap focusing on these two conditions and examining the veracity of the Porter's hypothesis using empirical evidence from UK and Chinese firms.

\subsection{Condition 1: The design of environmental regulations}

The design of environmental regulations is of crucial importance. As Williamson (1999) has argued, regulations are a form of governance structure, usually combining elements from the extremes of market and hierarchy. The market mode is characterised by high-powered incentives with little administrative control, while the hierarchy combines low-powered incentives and excessive administrative control. Regulations could be considered as a hybrid structure combining elements of market and hierarchy.

Only a handful of studies have sought to empirically examine the impact of regulation design (e.g. Costa et al., 2010; Crotty and Smith, 2006; Lopez-Gamero et al., 2010; Majumdar and Marcus, 2001; Partzsch, 2009) on the Porter hypothesis. Regulations need to be 'innovation friendly' (i.e. with flexibility as a central tenet underpinning innovation) (Majumdar and Marcus, 2001). Following Majumdar and Marcus (2001), environmental regulations are classified into two: flexible and inflexible. Flexible regulations are innovation friendly encouraging firms to develop appropriate new processes/products to meet regulatory requirements, whereas inflexible regulations prescribe specific processes/products to achieve a particular outcome. In Williamson's (1999) view, flexible regulations have a higher level of market governance while inflexible regulations are dominated by elements of hierarchical governance.

If environmental regulations specify that any company wishing to produce a particular product or substance must use a certain technique to reduce its pollution, then the company is forced into paying for the pollution control equipment. Examples of such inflexible regulations are the air and water pollution regulations in the United States prior to 1990 as demonstrated by Majumdar and Marcus (2001). Majumdar and Markus (2001) have illustrated that these regulations have forced polluters to conform to pre-specified standards or else face closure. Obviously, this kind of inflexible regulation does not encourage creativity and innovation in firms: any desire to innovate and to develop new techniques that are less harmful is nullified.

On the other hand, flexible regulations specify only the desired outcome but leave the 'how' to the individual firm. Majumdar and Marcus (2001) advance the solid waste regulations in 
the United States as an example of flexible regulation because it offers firms discretion as to the 'how', provided the challenging pollution prevention goals are achieved. More recent regulations, such as the European Union-wide greenhouse gas Emissions Trading Scheme (EU-ETS) Regulations 2003/05, could also be classified as flexible because these regulations set an overall cap on the permissible levels of emissions, and then grant permits to businesses for trading (Zhang and Wei, 2010). In this case firms may choose to continue with the status quo and simply purchase additional end-of-pipe equipment in order to meet the targets. In contrast, a proactive firm might attempt to redesign the process altogether, so that such endof-pipe pollution abatement expenditure is avoided. The latter approach is likely to enhance a firm's competiveness by reducing operating costs as well as boosting its green marketing leadership credentials (Hart, 1995).

The consensus suggests that flexible regulation enables a firm to take either the dynamic and innovative route, or the reactionary route deploying conventional tactics (Haughton and Browett, 1995; Lopez-Gamero et al., 2010). On the other hand inflexible regulations, through tight prescription, are likely to stifle innovation-encouraging compliance.

\subsection{Condition 2: Firms' capabilities and innovation}

The other key dimension of the Porter hypothesis is the firm's behaviour - how they choose to respond to environmental regulations or other pressures to improve their environmental performance. If regulations are flexible enough firms can choose to adopt a dynamic approach to improving environmental performance by: (1) redesigning polluting production processes; (2) the adoption of environmental management practices such as energy conservation and waste management; and (3) strategically positioning themselves as a leader in environmental protection (Wu et al., 2012). Alternatively, they might choose to carry on as before, paying increasing taxes and levies resulting from the regulations, and/or implementing costly end-of-pipe solutions.

In general, if the firm takes a dynamic approach, flexible regulations could provide opportunities for innovation, which in turn would improve financial performance. This paper draws on the literature on innovation strategy (Cassiman and Veugelers, 2006; Li and Atuahene-Gima, 2001) to define dynamic capability as the firm's capabilities to reconfigure its internal and external resources and competencies to deal with changing environments (e.g. Teece et al., 1997). Here the environment changes are triggered by new or modified environmental regulations.

The dynamic approach is supported by the dynamic capabilities view (DCV) of the firm (Eisenhardt and Martin, 2000; Teece et al., 1997). This theoretical paradigm suggests that 'the competitive advantage of firms rests on distinctive processes (ways of coordinating and combining), shaped by the firm's (specific) asset positions (such as the firm's portfolio of difficult-to-trade knowledge assets and complementary assets), and the evolution path(s) it has adopted or inherited' (Teece et al., 1997: 509). Such processes enact a firm's capabilities, which include a firm's organisational skills and ability to innovate. In this view, having the ability and willingness to develop innovative solutions, as well as the flexibility in management systems necessary to implement such solutions, can be considered as valuable capabilities. Firms with such capabilities will be able to use flexible regulations as an opportunity to deploy and reconfigure their resources to develop a competitive advantage. 
A small number of studies have investigated the strategic choices of firms in response to environmental regulations. They conclude that firms deploying their resources in a proactive manner will benefit more from, and are able to cope better with, the requirements of environmental regulations (Christmann, 2000; Klassen and Whybark, 1999). Such proactive environmental strategy is characterised as a dynamic capability by Aragon-Correa and Sharma (2003).

In conclusion there is a paucity of empirical research examining the regulatory design and the capabilities to innovate simultaneously, despite the fact that the available literature indicates that both of these factors are important (Black et al., 2010; Janicke, 2008; Lopez-Gamero et al., 2010). This paper stresses the importance of the two conditions of the Porter hypothesis that underpin the relationship between environmental regulations, innovation and the financial performance of firms.

\section{Broad a priori assumptions}

Focusing on the two premises of the Porter hypothesis, this paper develops a range of a priori assumptions on the nature of the relationships between environmental regulations and other drivers of environmental innovation, environmental management practices (EMPs) and firm financial performance.

Specifically: (1) inflexible regulations are likely to encourage firms to pursue costly compliance; (2) flexible regulations, along with other pressures that exist to improve environmental performance, provide firms with the opportunity to respond dynamically, and help them to innovate and invest in sound EMPs, potentially improving their financial performance while simultaneously improving their environmental performance; (3) alternatively, despite the presence of flexible regulations, firms can take a reactionary attitude and improve their environmental performance via costly pollution-control methods that ultimately harm their financial performance (Black et al., 2010; Christmann, 2000; Haughton and Browett, 1995; Klassen and Whybark, 1999; Lopez- Gamero et al., 2010; Majumdar and Marcus, 2001).

This paper now seeks to address the appropriateness of these broad a priori assumptions for thinking about environmental regulations and their effects on regulated firms. The evaluation was undertaken via a qualitative case-study methodology in nine firms in the UK and China.

\section{Research method}

According to Eisenhardt (1989), building case studies offers a good basis for developing theory, particularly when the subject is new, because the rich information generated can usually produce testable novel theories. Given the relative complexity of the broad a priori assumptions, the most appropriate methodology was the case study (Eisenhardt, 1989; Ketokivi and Choi, 2014). Moreover, to ensure the propositions of this paper are theoretically generalisable to a wider international context, case studies were conducted in both the UK (a developed economy) and China (an emerging economy) (c.f. Ozsomer and Simonin, 2004; Zhu et al., 2003). 
Although differences in regulations exist at a detailed level, businesses in both countries are nowadays subject to increasingly significant environmental regulations. This is especially true for China: in taking more and more responsibility for global climate change and environment protection, its government is introducing increasingly stringent regulations.

This study followed an inductive approach. Based on the suggestions of Eisenhardt (1989) the study adopted theoretical sampling. Thus in line with inductive logic, the choice of the case companies was based on a thorough understanding of the nature of the business and relevance of the business to the research theme to ensure the cases selected were capable of extending the emergent theory based on the Porter hypothesis.

First, a case study protocol was developed based on the broad a priori assumptions, which specifies the case company selection criteria and a set of interview questions (see Appendix A). Coarse-grained selection criteria were agreed between the authors, so that (1) case firms are typical or major market players, and they should all have sustainable development on their agenda either incorporated in their corporate strategies or embedded in their production processes; (2) case firms are regulated by various environmental regulations, and the environmental regulations should have a direct impact on their businesses; (3) R\&D and innovation are essential for case companies' competitive advantage, with environmental protection as a major key performance indicator for innovation.

Second, 170 UK companies and 100 Chinese companies were initially identified using the FAME database (UK) and Mingluji and Chinainfo databases (China) by two co-authors following the coarse-grained criteria.

Third, finer grained shortlist criteria were agreed between the authors, so that (1) the sustainable development strategies of case companies are explicit and in the public domain;

(2) case companies should have explicit strategies for R\&D innovation and be leading players in their own sector or region; (3) case companies should be subject to a range of environmental regulations locally or nationally. Eleven UK and ten Chinese companies were then shortlisted based on the second stage-screening by the co-authors, so that noncomparable companies were removed from the list. Telephone or email invitations were sent via the contacts identified through the FAME database, Mingluji.com and Chinainfo.org. Eventually, five UK companies and four Chinese companies agreed to participate. Each author independently checked case companies' profiles to ensure compliance with the selection criteria using secondary sources, such as news reports, company websites, annual reports and government announcements.

Fourth, following case-study approaches in the literature (e.g. Chen and Li-Hua, 2011), indepth interviews with these companies were conducted between September 2009 and July 2014. Interviewees were senior managers or middle managers with specific responsibilities related to environmental management, or environmental management was embedded in their roles. At least one interview was conducted for each organisation.

Although the case-study companies operate in very different sectors and in two different countries, for all of the case companies environmental regulations are becoming increasingly stringent, and have the potential to impact on their business operations and competitive position. Thus the case companies have a rich experience in dealing with environmental regulations or in developing innovative ideas in response. Their experiences were used as the 
basis for developing a conceptual framework and in drawing implications from the data for both policy makers and managers.

An a priori sample of nine case-study companies could limit the empirical generalisability of the study. However, the rich tapestry of data based on the insiders' views generated from indepth interviews with experienced senior managers in the two countries offers a good basis for reaching some general conclusions in line with other studies (Angel and Rock, 2005; Chen and Li-Hua, 2011; Dobrov, 1978; Storper et al., 1981). According to Eisenhardt (1989), four to ten cases are the norm of the inductive case-study approach. Too many cases may, on the other hand, increase the difficulty for researchers in coping with the complexity and volume of data.

\subsection{Data collection and analysis}

The interview questions were developed in both English and Chinese, following a translation-back-translation process (Maxwell, 1996). Prior to the main field work, the questions were pilot tested using a pool of academics and industrialists, and the appropriate changes made. The main interviews were semi-structured to maximise interaction with interviewees. The fourteen interviews (six with UK companies, and eight with Chinese companies, see Appendix B) each lasted between 45 and 60 minutes, and were conducted face to face or by telephone. At the beginning of the interview, interviewees were briefed and introduced to the definitions of flexible and inflexible environmental regulations. The interviewees were assured that their responses would be treated confidentially and anonymously. Each interview was recorded using a digital voice recorder and transcribed. The Chinese transcriptions were translated into English following a translation-backtranslation process. Transcriptions were read and cross-checked by two of the authors, and then sent to the interviewees for validation. Based on interviewees' feedback, the necessary corrections were made.

Following the validation of interview transcripts, a template analysis was conducted using the NVivo 8 software (King, 2004). First, based on the broad a priori assumptions and the casestudy protocol, two of the authors identified the main concepts independently to construct an initial template (see Table 1). Since the initial template was broad enough, the concepts identified by the authors were largely consistent despite the occasional issue having been extracted by one but not the other author.

Insert Table 1 about here

This initial template was then used as the starting point and a guide for an in-depth analysis of the interview transcripts by one of the authors using the NVivo software. Initial codes were added to the interview transcripts based on the main concepts identified in the initial template. These codes were further refined to identify new emerging concepts for the development of the final template. This was an iterative process involved revising the initial template through adding new codes, removing existing codes and moving concepts from one coding area to another, while reviewing the detailed quotations of the interviewees. Towards the end of this process, the second author was asked to evaluate the relevancy of the emerging concepts. The final template (see Table 2) was achieved when no new concepts emerged and both authors 
were confident that the emerging themes were exhaustive and were supported by relevant quotations.

Insert Table 2 about here

The authors then evaluated the final template collectively and assessed the nature of the relationships between environmental regulation, innovation and financial performance from the cases. The concepts and preliminary findings were cross-checked with secondary information from relevant documents of the case-study companies (e.g. annual reports and companies' websites corresponding to the case-study period (September 2009 to July 2014) and also using external sources such as newspaper articles, editorials, government announcements and online reports during this period. Annual reports and third-party databases, such as the FAME database, were used to obtain financial data of case-study companies.

The case study results formed the basis of the development of propositions and the conceptual framework. These propositions and other findings were discussed in a post-hoc workshop with participation from a number of manufacturers in the UK, and the deliberations of the workshop participants were very closely in agreement with the findings of this study. The following sections discuss the case study results and propositions and the conceptual framework.

\section{Results}

This section discusses the findings, examines the extent to which they are aligned with the broad a priori assumptions and identifies notable variations in order to formulate the conceptual framework.

\subsection{An overview of the case-study companies}

Qualitative research methodology requires a detailed analysis of case-study companies, which forms the basis for within-case analysis (Eisenhardt, 1989). Accordingly, an overview of the nine case-study companies is presented below (see Appendix B for a summary).

CHEM Co. is a chemical company manufacturing construction chemicals, pest control solutions, polyurethane systems, industrial coatings, pigments and products that enhance industrial processing. It employs nearly 2,000 people in its UK and Ireland operations, and its turnover was over $€ 2$ billion in 2011 . Sustainability and social responsibility are important company goals, and it states that it combines economic success with environmental protection and social responsibility through science and innovation. It has been included in the Dow Jones Sustainability World Index for more than ten successive years. Over $€ 1$ billion have been invested in R\&D each year. Although the company regards sustainability through innovation as a major driving force for business growth, another focus of the innovation is to meet increasingly strict regulations, stating in its recent annual report that it anticipates increasing regulation risks due to the cost-intensive regulative procedures. The interviewee highlighted the Control of Major Accident Hazards (COMAH) Regulations, the Carbon 
Reduction Commitment Regulations, and the Waste Electrical and Electronic Equipment Recycling (WEEE) Regulations - although the interviewee also mentioned that the firm was subject to most environmental regulations.

ELEC Co. is one of the UK's largest electricity and gas suppliers to domestic and business customers. It generates electricity and hence is subject to regulations covering manufacturing companies. Moreover, it is one of the largest producers of low-carbon and nuclear-generated electricity in the UK. Its UK turnover is more than $€ 9$ billion. Part of the company's mission is to bring low-carbon energy to the market, so sustainability is a major strategic agenda. The company regards economic viability as important to its environmental and social viability, and has developed a systematic agenda of sustainability commitments. Such commitment is to be realised through reducing carbon emissions and improved waste management, and developing better relationships with customers, employees and local communities. Innovation ostensibly plays an important role in ELEC Co.'s sustainable development strategy. The focus of its R\&D is on consolidating and developing a carbon-free energy mix, fostering flexible and low-carbon energy demand, and providing smarter energy management systems. Because energy production and consumption are stringently monitored by the regulators and various stakeholders, compliance to numerous regulations is critical. During the interview, the interviewee highlighted that the firm was subjected to nearly 260 environmental regulations and specifically mentioned the following: Radioactive Substances Act 1993 governing nuclear plants, Production Prevention and Control (PPC) Regulations (now Environmental Permitting Regulations 2007), EU Emissions Trading Scheme, Packaging (Producer Responsibility) Regulations and the WEEE Regulations.

RAIL Co. is a world-leading manufacturer of rail vehicles and related products, such as propulsion and controls equipment, transportation systems and rail control solutions. It frequently alludes to the importance of corporate social responsibility and sustainable development and its incorporation in the corporate strategy. Innovation is seen as the driving force of business growth, while developing safe, efficient and environmentally responsible products is regarded as the central target of its product innovation. RAIL Co. also highlights the importance of collaboration with its supply-chain partners and various stakeholders to develop its business responsibly. The company is aware of the increasingly stringent environmental regulatory requirements or enforcements, and may incur additional costs in order to be compliant with such requirements or enforcements. Hence it is sensitive in dealing with safety and environment related issues in its business operations. During the interview, the interviewee mentioned a long list of regulations affecting the firm, including the Local Air Pollution Prevention and Control (LAPPC) Regulations, the Packaging Waste Regulations 1997, Hazardous Waste Regulations, Environmental Protection Act Section 34 Duty of Care, the Environmental Permitting Regulations, the Control of Pollution Oil Storage Regulations, the Water Industries Act, and the Fluorinated Gases Regulations.

SUPR Co., headquartered in London, is engaged in manufacturing and developing innovative and practical high-temperature superconductor (HTS) applications around the world. The company is publicly listed with a turnover of over $€ 2.6$ million in 2010 . It emphasises the importance of innovation to its competitive position and invests a significant proportion of its revenues in $R \& D$. It receives substantial support for its $R \& D$ activities in the form of government grants, which are generally policy driven. Hence its business is significantly affected by governmental regulations and policies. Deployment of a sustainable production process is a key competitive advantage. In recognition it has received major innovation and environmental prizes from various governmental bodies. The interviewee mentioned that the 
firm faced regulations similar to other comparable businesses but did not highlight any regulation in particular.

TEL Co. is a UK-based subsidiary of a large Chinese private ICT company, which offers a range of new generation end-to-end telecoms and IT network solutions to mobile and fixed line operators as well as enterprise networks. It has 15 offices across the UK employing close to 1,000 people. As a Chinese company operating in the UK it has to meet the environmental performance standards of both the European Union and China. It has adopted a proactive approach to meeting the most stringent environmental regulations across nations to avoid future problems due to more stringent standards. The company is keen to develop and adopt innovative ideas and also to collaborate with various stakeholders to reduce carbon emissions and improve the energy efficiency of its products. As indicated by the interviewee, the company is subject to most of the UK and EU environmental regulations. It is also subject to Chinese regulations such as the Environmental Protection Law of China, the Cleaner Production Promotion Law (CPPL) and the Energy Saving Law, as many of its products are sourced from China.

TEX Co. is one of the leading Chinese textile and garment material companies based in Zhejiang province in China. Its products range from textile materials and garment components, to a whole range of small consumer products and appliances, which are exported around the world. The company has over 3,000 employees and an annual turnover of over RMB 4 billion (around $€ 0.6$ billion). It is putting more and more effort into improving the sustainable performance of its operations, because of increasingly stringent local regulations as well as the increasing environmental requirements of purchasers, especially those from North America and Europe. Since the company is operating in a traditional sector it has to comply with increasingly stringent regulations, such as the Air Pollution Prevention Law, the Water Pollution Prevention Law, and the Cleaner Production Promotion Law (CPPL), which enforces more specific standards and guidance notes enacted by Chinese Ministries, such as the Emission Standard for Industrial Enterprises Noise at Boundary, the Cleaner Production Standard (sector specific) and the relatively newly introduced Corporate Environmental Credit Evaluation (Trial).

CHXIN Co. is a family owned medium-sized pharmaceutical company established in the early 1990s and based in Henan province, China. Its products range from traditional Chinese medicine patent prescriptions to herbal medicine materials. It sources raw materials nationally and internationally as well as from its own 165-acre herbal plantation. It is mainly regulated by the China Food and Drug Administration, which issues Good Manufacturing Practices (GMP). The GMP has to be renewed every five years taking into account updated standards. Minimising environmental impact is one important aspect of the GMP certification. The company is also subject to the Corporate Environmental Credit Evaluation (Trial), which is a new regulatory guideline that imposes more explicit responsibilities and penalties for lack of compliance with environmental regulations. In addition, due to the rapid expansion of manufacturing plants in the last decade, it has to comply with the requirements of the Environmental Impact Assessment (EIA), which enacts various environmental regulations, such as the Emission Standard for Industrial Enterprises Noise at Boundary, Integrated Emission Standard of Air Pollutants, the Cleaner Production Standard (sector specific), and the Integrated Wastewater Discharge Standard. Notwithstanding regulation, the company is actively adopting closed-loop manufacturing, for example by recycling and reusing herbal residues into the manufacturing process or into generating related by-products. 
KLUN Co. is a large Chinese pharmaceutical PLC headquartered in Sichuan province, China. It is listed in the Shenzhen Stock Exchange with 87 subsidiaries throughout China. KLUN Co. specialises in the manufacture and sale of 562 different products, including intravenous (IV) solutions and lyophilised sterile powders for injections, small volume parenterals, etc. With its own research institute, the company has invested heavily in R\&D, including developing environmentally friendly IV solutions. In addition to GMP certification, which is compulsory for all pharmaceutical companies, the company has acquired various other certifications, including ISO 9000, ISO 18000 and the ISO 14000 Environmental Management Standard. Like other pharmaceutical companies in China, the company has to comply with the Air Pollution Prevention Law, the Water Pollution Prevention Law, and the Cleaner Production Promotion Law (CPPL), which enforces more specific standards and guidance notes enacted by Chinese Ministries, such as the Emission Standard for Industrial Enterprises Noise at Boundary, the Cleaner Production Standard (sector specific), and the newly introduced Corporate Environmental Credit Evaluation (Trial). Its size creates slack resources, enabling it to invest in and develop product and process environmental solutions.

OIL Co. is a large edible oil company based in Henan province, China, with an annual production capacity of 700,000 tons and an annual turnover of RMB9 billion (around $€ 1.2$ billion). Its main products include edible oil, soybean meal and soybean lecithin, which are sold nationwide. The production of its edible oils employs a hot-pressed method relying on a coal-burning boiler, which is its main source of pollution. The company is subject to the Air Pollution Prevention Law, the Water Pollution Prevention Law, the Cleaner Production Promotion Law (CPPL), and those more specific standards and guidance notes, such as the Emission Standard for Industrial Enterprises Noise at Boundary, the Integrated Emission Standard of Air Pollutants, the Cleaner Production Standard (sector specific), and the Integrated Wastewater Discharge Standard. According to the interviewee, the company has introduced new technologies, such as heat recycling and emission control, to improve production efficiency and to reduce carbon emissions. While the majority of its materials and residues can be recycled and reused in producing profitable by-products, reducing its environmental impact as stipulated by tougher and tougher governmental regulations is a challenge.

In summary, all nine case companies have sustainability on their agenda, either incorporated in their corporate strategies or embedded in their production processes. In all cases, R\&D and innovation contribute to their competitive advantage. They all invest heavily in innovation, with environment protection as a major key performance indicator for innovation. Although they operate in very different sectors, environmental regulations are becoming increasingly stringent for all of the companies and they have the potential to impact on their business operations and competitive position. Moreover, the case companies all have rich experience in dealing with environmental regulations and in developing innovative ideas in response. Their experience was used as the basis for developing a conceptual framework. Implications were also drawn from the data for both policy makers and managers. The cross-case analysis, in which the themes/concepts presented in Tables 1 and 2 are compared using the interview results of the case companies, is discussed in the following sections.

\subsection{The impact of environmental regulations on innovation and the adoption of EMPs}


It was found that environmental regulations, through a variety of mechanisms, affect the innovation and adoption of EMPs in both the UK and China. The influence of regulations can be positive or negative through altering the balance of incentives offered to companies. Increasing the costs of energy or waste disposal, for example, renders energy-saving and waste-reduction measures increasingly attractive. The interviewee from SUPR Co. discussed an instance of process redesign to reduce the production of hazardous waste, the disposal of which is closely regulated, thereby making the company financially more competitive.

'We had managed to eliminate one of the interim processes, and in that interim process you would produce... hazardous materials... that's great for us because we are avoiding the need, unlike our competitors, to produce this toxic material. That's also beneficial for us because if you reduce the toxic material you don't have to pay to handle it, or pay to clean it up, or pay to exhaust it in a certain way, which we avoid. So we have cost savings in our manufacturing base.'

On the other hand, the quote below provides an example of poor regulatory design preventing improved environmental behaviour and culminating in increased financial and administrative cost for the firm. The interviewee from RAIL Co. pointed out that with some regulations, the administrative burden of simple compliance was so high that it reduced the focus on improving the company's environmental performance to secondary.

'The absolute bottom line is that we could get prosecuted if we do not pay the right amount of Packaging Recovery Notes (PRN), therefore our priority for today is to gather the right data to calculate the amount of PRN we have to buy. And unfortunately that is all I have time for, the time I'm spending calculating that tax, means that I am not able to spend that time speaking to our major suppliers to try to get them to reduce our packaging.'

The same concern was expressed by the interviewee from CHXIN Co.

'Year on year there are new standards introduced by the China Food and Drug Administration (CFDA) or the Ministry of Environmental Protection (MEP). Normally, the new standards are higher standards for environmental protection. We will have to improve our processes and standards in response. Normally the new standards are achievable, but sometimes new testing facilities will have to be installed. The production process may not be affected much. However, the testing facilities will be affected. For pharmaceutical industry, the cost on testing is enormous, sometimes beyond your imagination. Much more training is also needed for that.'

Given there are constant updates of regulatory standards, the company has to dedicate extra resources to cope with the inspections. Moreover, environmental regulations can indirectly affect innovation by altering the other pressures that can lead to environmental innovation and the adoption of EMPs. For instance, regulations leading to the adoption of EMPs create a more level playing field between environmentally responsible and irresponsible firms (e.g. CHEM Co., TEL Co., KLUN Co.). Thus even a less environmentally proactive firm is more likely to engage in environmental innovations in response to appropriate environmental regulations.

It was also found that some companies undertake innovative voluntary actions in order to improve their environmental performance as a pre-emptive response to the possibility of new regulations, partially to weaken future regulations (e.g. CHEM Co., TEL Co., and KLUN 
Co.) or to avoid any future surprises as a result of a sudden increase of standards (e.g. TEX Co. and CHXIN Co.). Despite being wasteful on resources (in terms of taking extra actions not necessarily needed to satisfy the current regulation) in setting higher internal standards, these voluntary innovative pre-emptive responses were commonly adopted by companies.

Regulations have also encouraged some firms to have formal innovative systems in place to collect and analyse environment-related data (e.g. RAIL Co. and KLUN Co.).

\subsection{Other determinants of innovation and adoption of EMPs}

The interviewee from ELEC Co. pointed out that the firm's environmental practices were not driven by regulations but by the firm's own sustainability agenda, which formed part of the strategic repositioning of the company. In other cases, e.g. CHEM Co. and TEL Co., EMPs were not driven by any particular regulations, but by the myriad regulations across different countries and regions of the world. The interviewees from both CHEM Co. and TEL Co. suggested that as multinational businesses the administrative burden of working to several different sets of environmental regulations was very great requiring them to follow the same stringent environmental standards globally. As the interviewee from TEL Co. suggested:

'Legal requirement is the bottom line. But we have put higher standard than that.'

Similarly, the interviewee from CHEM Co. said:

'One of the practical issues we have that actually steps us away from legislation, is to try and get the finer points of the legislation complied with; it's a problem because obviously it depends on where you are, both sometimes regionally as well as nationally. Therefore we've tended to have our own quite high standards and work on the principle that we're probably a better standard than anything there is within the legislation. It's actually an easier way of dealing with things from a management perspective than it is worrying about what the legislators and local enforcers are going to ask for.'

These examples support the use of global standards for environmental performance reinforcing points made by other scholars (Angel and Rock, 2005).

The growth of environmental awareness combined with economic pressures to reduce costs and improve competitiveness are major drivers of EMP adoption (Hart and Dowell, 2010). As discussed earlier, regulations that increase the cost of energy as well as the cost of pollution can increase the return on EMPs further (e.g. Ramanathan and Akanni, 2015).

A number of case companies targeted the growing number of environmentally conscious customers and attempted to stay ahead of the increasingly stringent environmental regulations curve by strategically positioning themselves as environmentally friendly with a view to increase their long-run market (e.g. CHEM Co., TEL Co., KLUN Co.). For example, KLUN Co. strove to become the market leader in producing innovative environmentally friendly large volume injection packaging products. TEL Co.'s unique selling point was its expertise in producing energy efficient data transmission devices. Many of the case companies suggested that customers' demand drove their attempts to produce greener products. This suggests that regulations with an eye to indirectly influence demand can encourage firms to adopt environmental innovation. 


\subsection{The impact of firms' capabilities on their responses to regulations}

In addition to the factors highlighted in Section 5.3, respondents identified internal resources and capabilities as factors influencing firms' choice in pursuing dynamic/proactive or reactive/compliance approaches to EMP. CHEM Co., for example, was able to deploy a more advanced EMP system compared to its competitors due to its capability to manage reconfiguration and slack financial resources. Such capability is considered as dynamic capability, because CHEM Co. is able to reconfigure its resources to more quickly respond to the external pressures. KLUN Co.'s ability to support a research institute enabled it to generate and promote new state-of-the-art technologies. In this sense, KLUN Co. is having dynamic capabilities at an institutional level to enable it to respond to the market and the external pressures more quickly and systematically. On the other hand, smaller companies, such as CHXIN Co., were unable to adopt more advanced low-emission technologies because of resource and finance constraints. As the interviewee from CHXIN Co. suggested:

'We have even considered using solar energy to replace traditional electricity. But think about the cost and the life cycle of solar panels. It is still expensive to us. We considered installing solar panels to our manufacturing plants. We can consume directly and also transmit excessive energy into the main power frame. But we know it will be a very good practice. For example, the solar panels on roof top can reduce the temperature of the plant when it is in operation; you know it is very hot especially in the summer. But the investment on solar panel is massive.'

The existence of formal environment management roles enabled firms to adopt EMPs more proactively. Intangible resources also played a critical role. Environmentally conscious and strategically ready firms were able to find resources to adopt a proactive approach to EMPs. The proactive EMP enacts a dynamic capability response to environmental regulations (Aragon-Correa and Sharma, 2003). The case companies appeared to adhere to environmental standards higher than those required by applicable regulations in order to avoid possible violations. Such strategy is undoubtedly backed up by extra tangible or intangible resources and capabilities deployed by the case companies.

\subsection{The impact of innovation and the adoption of proactive EMPs on firms' financial performance (private benefits of sustainability)}

Some of the EMPs adopted by case companies had a beneficial impact on firms' financial performance (private benefits of sustainability). Increasing energy efficiency, or redesigning production processes to produce less hazardous waste, produced benefits outweighing the costs. Some of the case companies used the production process waste as inputs to other processes, minimising waste and transportation and maximising energy efficiency (e.g. CHEM Co., CHXIN Co. and OIL Co.). As mentioned by the interviewee from CHEM Co.:

'I term it "everything connected to everything else". The idea being "no waste" or "nothing lost". And it also strategically links into the idea that you start centralising things, because it means stuff doesn't have to be transported.' 
There were also examples of selling waste products to other companies but not for environmental reasons, simply because it made financial sense to do so (e.g. RAIL Co., CHXIN Co. and OIL Co.).

Environmentally friendly product innovation also offered business opportunities to all the case companies. As firms become more heavily regulated or seek to be more competitive, products or production processes with better energy efficiency become increasingly attractive. For example, TEL Co. and KLUN Co. have reportedly increased their market share by effectively integrating eco-friendly concepts into their products. As stressed by the interviewee from SUPR Co.:

'If the aluminium or copper industry is included in some sort of a carbon scheme... then obviously our machine, the payback from our machine, will be far improved.'

\subsection{The impact of environmental regulations on firms' private sustainability benefits: reactive practices by firms}

The case studies also reveal the impact of environmental regulation on companies' financial performance (private sustainability benefits) that are the result of reactive pollution control and other reactive EMPs, rather than innovation or the adoption of proactive EMPs.

Some regulations were identified as imposing significant financial and administrative costs. The interviewee from ELEC Co. said that the command-and-control nature of some regulations (specifically the Integrated Pollution Prevention and Control Regulations, which in some cases necessitate a plant to use the 'best available technique') can go so far as to make a plant financially non-viable. By contrast, market-based instruments imposed a much lower cost burden on the company.

The interviewees from case companies suggested that, even if regulations were relatively flexible, the timescale surrounding their implementation was crucial in determining the cost to the company (e.g. CHEM Co. and CHXIN Co.). Shorter time scales reduce the level of flexibility in regulations and force even innovative firms to be reactive as they do not have enough time to innovate. In some situations, even relatively small costs can cause havoc if they have not been budgeted for. As mentioned by the interviewee from CHEM Co.:

'In general if we know it's (a new environmental regulation) coming we can build it into our business models... But it's when things sneak up on you. The Carbon Reduction Commitment regulations have just appeared. In the UK it's probably going to cost us, rough calculation, $£ 20,000$ to $£ 25,000$, which in the bigger picture is not a lot of money, but the trouble is its completely unbudgeted.'

Sudden regulation changes can spring a surprise on companies forcing them to react administratively (e.g. RAIL Co.). The interviewee from CHEM Co. pointed out that, especially at smaller sites, environmental auditing can prove to be very administratively costly, and could potentially cause more environmental damage than it prevents. 
'When I've got a site that has only got four or five people, when there's only a sales office with only two people permanently in it, you know, not much bigger than this room1, asking us to do multilevel environmental reporting does not help either the environment or our business. It's more environmentally insecure to do the reporting than not to do the reporting.'

Obviously, in this case, the cost of environmental reporting to the company is viewed as greater than the associated environment-related benefits such reporting is expected to result in.

The case studies suggest that regulations can be inflexible not just in the sense of rigid command and control; they can also be inflexible as a result of being sudden, ambiguous and overcomplicated, and sometimes due to the sheer number that may be applied to an industry. Such inflexible regulation designs can create significant administrative burden and may not necessarily enhance the environmental performance of firms.

\section{Discussion, propositions and conceptual framework}

This study has focused on two important conditions of the Porter hypothesis: the design of environmental regulations and firms' innovation capabilities. Starting with three a priori assumptions derived from the literature, an inductive case-study approach has been used to understand the mechanisms through which environmental regulations influence the environmental behaviours of firms. The qualitative study was conducted with nine firms in the UK and China.

The results have not only confirmed the validity of the three broad assumptions but have shed further insights on the influence of environmental regulations. The three assumptions appear to be valid: inflexible regulations force firms to be reactive and adversely affect financial performance, flexible regulations help innovative firms in meeting regulations as well as improving performance, firms without innovative capabilities are not able to improve their financial performance even with flexible regulations. The results show that it is vital that any environmental regulations promulgated by government foster innovation in firms by providing sufficient flexibility to firms. Some prominent additional findings beyond these a priori assumptions include (1) a multi-country context to verify these assumptions, (2) firms may find setting their own high environmental standards to be more useful than trying to comply with all the different levels of regulation at work in different countries or regions, (3) any given regulation (or set of regulations) cannot be characterised on a dichotomous scale (as purely 'flexible' or 'inflexible'), and (4) a similar sliding scale would be more appropriate to capture how firms react (proactive or reactive) to environmental regulations. These results are further discussed in the rest of this section.

\subsection{Impact of regulatory pressures}

The case studies have demonstrated that firms can either take a dynamic approach to turn regulatory and other pressures into innovative actions, or a reactive approach to simply

\footnotetext{
${ }^{1}$ The room in which the interview was conducted was a small seminar room with two tables and a few chairs. Its size was approximately $2 \mathrm{~m} \times 4 \mathrm{~m}$.
} 
comply with regulatory items. The choice of either approach is decided by resource capabilities, which is used to shape the first proposition.

Proposition 1: Depending upon firms' internal resources and capabilities, firms will approach flexible regulations dynamically to develop innovative solutions or a reactive approach of pollution control. The choice of approach will not only affect the private sustainability benefits of firms but also impact on public sustainability benefits.

This proposition will be further elaborated on in the next few subsections.

\subsection{Regulatory design and innovation}

The importance of regulatory design was alluded to by all respondents. Respondents preferred market-orientated mechanisms because they allowed firms to address environmental issues in their own way. Administrative costs imposed by rigid regulations were identified as significant, adversely affecting financial performance. The timescales over which regulations are introduced was further identified as being an issue, as shorter time scales reduce the level of flexibility in regulations and force even innovative firms to be reactive as they do not have enough time to innovate.

This study also broadly identified a positive link between innovation and financial performance. Energy and waste-efficiency measures appeared to improve the bottom line, as did process innovations that reduced hazardous waste, and product innovations that exploited the desire (or requirement) for improved product environmental performance. Thus the following additional propositions emerge from the case studies.

Proposition 2: When the government enacts environmental regulations that focus on outcomes but do not prescribe the processes (i.e. flexible regulations), and when firms approach such flexible regulations dynamically and develop innovative solutions, the firms will experience a positive impact on financial performance and private sustainability benefits. The private sustainability benefits of firms will also improve public benefits.

Proposition 3: Firms that take a reactionary approach towards regulations will incur significant expenditure in meeting the requirements of these regulations, and suffer an adverse impact on their financial bottom line irrespective of whether the regulations are flexible or inflexible.

Proposition 4: Firms that approach other environmental pressures (such as customer demand, strategic position and economic pressures) dynamically and that innovate will experience a positive impact on their financial performance and private sustainability benefits. Private sustainability benefits of firms will also improve public benefits.

Proposition 5: Inflexible environmental legislation that stipulates the use of the 'best available' techniques leads to higher capital expenditure and other administrative costs to firms, and hence adversely affects financial performance and reduces private sustainability benefits. Public sustainability benefits will also be adversely affected.

All these propositions have implications for policy makers in terms of regulatory design. Furthermore, they all contribute to the generation of the conceptual framework that stresses 
the importance of flexible regulatory design for innovation - leading to better private sustainability benefits. This study identified the links between environmental regulation and innovation. The other (non-regulatory) pressures to improve environmental performance have been backed up in discussion: the economic pressures (because waste reduction involves both cost reduction and improved environmental performance) were foremost, but customer demand for greener products and the strategic positioning of a company as a market leader in environmental issues also featured.

\subsection{Conceptual framework}

The empirical findings above form the basis for the conceptual framework (shown in Figure 1), showing the complex interconnections between environmental pressures on firms and their reactions. The threat of regulation drives firms to take voluntary action to avoid future regulation. Inflexible regulations escalate the administrative burden reducing the private sustainability benefits for both proactive and reactive firms. For firms following reactive pollution-control practices, the excessive administrative costs generated are unlikely to be offset by the potential benefits. These findings are not unique to environmental regulations. For example, Almeida and Carneiro (2009) found that stricter labour regulations have led to higher unemployment in Brazilian firms.

Insert Figure 1 about here

The framework extends the original broad a priori assumptions with additional complex links identified through conduct of the case studies. For example, the administrative cost of complying with regulations at work in different countries or regions is such that firms establish the highest standards, or in some cases higher standards than the highest required. Such a response is only feasible if firms possess excessive resources. This relationship could be interpreted in terms of a dynamic setting where such a response reduces some of the administrative cost of dealing with regulations.

It is contended that the conceptual framework shown in Figure 1 offers an appropriate structure for evaluating environmental regulations from different perspectives - those of research, policy or a manager affected by such regulations. It is worth pointing out that any given regulation (or set of regulations) faced by a company cannot be characterised as purely 'flexible' or 'inflexible'. In reality, all regulations have more or less flexible elements to them. Therefore a linear two-dimensional spectrum would be more appropriate than two distinct categories to characterise regulations. The same is true to a lesser extent of the difference between dynamic and reactionary approaches to the environmental challenges. For example one firm may switch between dynamic and reactionary approaches overtime or when encountering different environmental regulations. In this case it is easier to categorise an organisation as one or the other, but a sliding scale would be more appropriate. It is proposed that the conceptual framework can be used for this purpose and as an approximation of the key issues involved.

The conceptual framework and the propositions closely support the theme of this special volume (Niesten and Lozano, 2015) by providing better understanding of the mechanisms for maximising private and public benefits of sustainability, and demonstrate an effective hybrid 
governance structure to enable firms to better integrate economic and sustainability benefits (Williamson, 1999). Public benefits relate to an overall reduction in environmental impact of production processes. Proposition 1 advocates that regulations may or may not increase positive externalities, decrease negative externalities or achieve the public benefits of sustainability depending on an adequate level of involvement from firms. However, all these propositions provide the key for understanding the drivers of private benefits of sustainability to individual firms. For example, Proposition 2 provides the most important requirements for improving private sustainability benefits: governments should enact flexible regulations while firms should take a dynamic approach to exploit the flexibility. Propositions 3 and 5, on the other hand, advocate that private sustainability benefits may not be realised if firms are not innovative enough. Finally, Proposition 4 highlights mechanisms for dealing with stakeholder pressures - being innovative with open mind, for example via developing improved production practices or more sustainable products or even improved productservice systems. Thus flexible regulations increase the incentive to firms in seeking innovative practices to enhance private sustainability benefits. The innovative practices can involve improved business models including, for example, new product-service combinations, effective involvement of partners in building sustainable supply chains, and improved design for sustainability whereby end-of-life processes are considered at the design stage itself. As highlighted earlier, the EU-ETS regulations offer economic incentives and are classified as an example of flexible regulations. Research on the economic impact of these regulations is continuing and there is a consensus that the overall influence of these regulations is generally positive but may need further economic adjustments and also a longer time frame to manifest (Zhang and Wei, 2010).

\subsection{Contributions and links to previous literature}

The propositions developed and the conceptual framework have anecdotal literature support, although few prior studies have focused on all of the constructs (i.e. flexibility of regulation, innovation and private sustainability benefits) simultaneously (Lopez-Gamero et al., 2010; Montabon et al., 2007; Visser et al., 2008).

This study has contributed to previous theory by verifying the complex issues surrounding the evaluation of the Porter hypothesis (Porter and van der Linde, 1995a, 1995b). It further contributes to the debate of effective hybrid governance structures that maximise the private and public benefits of sustainability (Williamson, 1999). Inflexible regulations cause excessive administrative burden, reduce private benefits of sustainability to firms and impact negatively on financial performance. The original Porter hypothesis did not put enough emphasis on the mechanisms for maximising private and public sustainability benefits. However, this study suggests that the dynamic capability will enable firms to better translate regulatory and other environmental pressures into opportunities for innovation and financial benefits.

Nevertheless, this study does not suggest that every firm with a dynamic mind-set will be able to engage in performance-enhancing innovation. Instead, it suggests that the application of the dynamic approach is resource and capability dependent. While doing so, ample support was found for the DCV (Eisenhardt and Martin, 2000), especially in the role of firms' resources and capabilities in Proposition 1. Previous research highlighted the importance of the DCV in explaining the varied strategic choices, but was limited in providing evidence to 
relate the reconfiguration of firms' resources with financial performance (Rugman and Verbeke, 2000). The theoretical predictions of the DCV have been supported in this study, because evidence was found for a positive impact on financial performance only when firms' resources and capabilities are effectively utilised to develop innovation.

\subsection{Limitations}

In spite of significant contributions, this study is not without limitations. First, although the interviewees had the required experience that could offset the limitations of the relatively small sample size, the sample size could be increased further. Second, it would be useful to conduct case studies with more firms from the same sector (e.g. chemical industries alone or electricity generation alone) so as to control for sectoral contingencies. Finally, findings from this qualitative study could be verified by using more quantitative oriented research, either by using secondary data collected by government, content analysis of the interview data, or by collecting primary data from questionnaire surveys. These findings form the scope for future research.

\section{Conclusions}

The results of the framework development and evaluation presented in this paper provide valuable insights into understanding the mechanisms by which government can use environmental regulations to help achieve the public benefits of sustainability (e.g. by reducing the pollution levels faced by society and the environmental impact of business activities) and also private benefits by influencing the environmental behaviours of firms. The results show that firms that take a dynamic approach to proactively managing their environmental performance are generally able to improve the private benefits of sustainability (e.g. by reducing consumption of energy and raw materials that result in reduced waste/pollution, or enjoying better market performance) better than those firms who do not prioritise environmental performance as highly. However, the fact remains that compliance with regulations has proved costly for all firms, and so it is in the area of regulatory design that most significant changes need to be made.

Specifically, there has been widespread support for (flexible) market mechanisms over command-and-control (inflexible) regulations. Instead of uniformly damaging all firms, and hence removing some of the incentives to improve their environmental performance, such flexible mechanisms allow firms that seek to improve environmental performance to reap private sustainability benefits, while penalising laggard firms.

It seems that the best way of encouraging innovation and environmental responsibility in firms is to focus on changing the conditions in which firms operate. Although not included in our propositions, the potential influence of regulations on 'other pressures' was featured in the case studies. In terms of the conceptual framework shown in Figure 1, this means focusing on regulations that affect the 'other pressures' to improve private sustainability benefits. Future research could investigate the influence of regulations on factors such as economic pressure, customer preferences for green products and strategic market leadership in environmental issues. These range from the most obvious (measures such as the Climate Change Levy imposing an additional cost on energy usage and thus strengthening the economic case for improved energy efficiency) to other less obvious links (such as the 
levelling of the playing field so that firms adhering to high environmental standards are not penalised, and the effects of customer preferences necessitating the production of environmentally friendly products). 


\section{Acknowledgements}

Part of the research for this paper was supported by funding from Nottingham Innovative Manufacturing Research Centre and the University of Bedfordshire Business and Management Research Institute. The authors wish to thank the anonymous reviewers and the editor of the special volume for their excellent and insightful comments. 


\section{References}

Almeida R., and Carneiro P., 2009. Enforcement of labor regulation and firm size, Journal of Comparative Economics, 37, 28-46.

Ambec, S. and Barla, P., 2006. Can environmental regulations be good for business? An assessment of the Porter hypothesis, Energy Studies Review, 14, 42-62.

Angel, D. P. and Rock, M. T., 2005. Global standards and the environmental performance of industry, Environment and Planning A, 37 (11), 1903-1918.

Aragon-Correa, J. A. and Sharma, S., 2003. A contingent resource-based view of proactive corporate environmental strategy, Academy of Management Review, 28 (1), 71-88.

Barbera, A. J. and McConnell, V. D., 1990. The impact of environmental regulations on industry productivity: Direct and indirect effects, Journal of Environmental Economics and Management, 18 (1), 50-65.

Bi, G. B., Song, W., Zhou, P. and Liang, L., 2014. Does environmental regulation affect energy efficiency in China's thermal power generation? Empirical evidence from a slacks-based DEA model, Energy Policy, 66, 537-546.

Black, A., Ramanathan, R. and Nath, P., 2010. Flexible environmental regulations and performance: The moderating role of innovation, Academy of Management Annual Meeting, Montreal, Canada, 6-10 August, 2010.

Blackman, A., Lahiri, B., Pizer, W., Planter, M. R. and Pina, C. M., 2010. Voluntary environmental regulation in developing countries: Mexico's Clean Industry Program, Journal of Environmental Economics and Management, 60 (3), 182-192.

Brunnermeier, S. B. and Cohen, M. A., 2003. Determinants of environmental innovation in US manufacturing industries, Journal of Environmental Economics and Management, 45, 278-293.

Cassiman, B. and Veugelers, R., 2006. In search of complementarity in the innovation strategy: internal R\&D and external knowledge acquisition. Management Science, 52 (1), 68-82.

Chen, D. and Li-Hua, R., 2011. Modes of technological leapfrogging: Five case studies from China, Journal of Engineering and Technology Management, 28 (1/2), 93-108.

Christmann, P., 2000. Effects of 'best practices' of environmental management on cost advantage: the role of complementary assets', Academy of Management Journal, 43 (4), 663-680.

Costa, I. and Ferrao, P., 2010. A case study of industrial symbiosis development using a middle-out approach, Journal of Cleaner Production, 18 (10/11), 984-992.

Costa, I., Massard, G. and Agarwal, A., 2010. Waste management policies for industrial symbiosis development: Case studies in European countries, Journal of Cleaner Production, 18 (8), 815-822.

Crotty, J. and Smith, M., 2006. Strategic responses to environmental regulation in the UK automotive sector, Journal of Industrial Ecology, 10, 95-111.

Debnath, S. C., 2015. Environmental regulations become restriction or a cause for innovation: A case study of Toyota Prius and Nissan Leaf. Procedia-Social and Behavioral Sciences, 195, 324-333.

Dobrov, G. M., 1978. Systems assessment of new technology for decision-making in government and industry part II: Case studies, Technological Forecasting and Social Change, 12 (2/3), 95-109.

Eiadat, Y., Kelly, A., Roche, F. and Byadat, H., 2008. Green and competitive? An empirical test of the mediating role of environmental innovation strategy, Journal of World Business, 43, 131-145.

Eisenhardt, K. M., 1989. Building theories from case study research, Academy of Management Review, 14 (4), 532-550. 
Eisenhardt, K. M. and Graebner, M. E., 2007. Theory building from cases: Opportunities and challenges, Academy of Management Journal, 50, (1), 25-32.

Eisenhardt, K. M. and Martin, J. A., 2000. Dynamic capabilities: What are they? Strategic Management Journal, 21 (10/11), 1105-1121.

Filbeck, G. and Gorman, R. F., 2004. The relationship between the environmental and financial performance of public utilities, Environmental and Resource Economics, 29 (2), 137-157.

Ford, J. A., Steen, J. and Verreynne, M. L., 2014. How environmental regulations affect innovation in the Australian oil and gas industry: Going beyond the Porter Hypothesis, Journal of Cleaner Production, 84, 204-213.

Gollop, F. M. and Roberts, M. J., 1983. Environmental regulations and productivity growth: The case of fossil-fueled electric power generation, Journal of Political Economy, 91 (4), 654-674.

Gray, W. B. and Shadbegian, R. J., 2003. Plan vintage, technology and environmental regulation, Journal of Environmental Economics and Management, 46, 384-402.

Hart, S. L.,1995. A natural-resource-based view of the firm, Academy of Management Review, 20 (4), 986-1014.

Hart, S. L. and Dowell, G., 2010. A natural-resource-based view of the firm: Fifteen years after, Journal of Management, 37, 1464-1479.

Haughton, G. and Browett, J., 1995. Flexible theory and flexible regulation: Collaboration and competition in the McLaren Vale wine industry in South Australia, Environment and Planning A, 27 (1), 41-61.

Horbach, J., 2008. Determinants of environmental innovation: New evidence from German panel data sources, Research Policy, 37, 163-173.

Iraldo, F., Testa, F. and Frey, M., 2009. Is an environmental management system able to influence environmental and competitive performance? The case of the ecomanagement and audit scheme (EMAS) in the European Union, Journal of Cleaner Production, 17, 1444-1452.

Jaffe, A. B. and Palmer, K., 1997. Environmental regulation and innovation: A panel data survey, Review of Economics and Statistics, 79 (4), 610-619.

Janicke, M., 2008. Ecological modernisation: New perspectives, Journal of Cleaner Production, 16 (5), 557-565.

Ketokivi, M. and Choi, T., 2014. Renaissance of case research as a scientific method. Journal of Operations Management, 32 (5), 232-240.

King, N., 2004. Using templates in the thematic analysis of text, In Essential Guide to Qualitative Methods in Organizational Research (Eds, Cassell, C. and Symon, G.) Sage, London, pp. 256-270.

Klassen, R. D. and Whybark, D. C., 1999. The impact of environmental technologies on manufacturing performance, Academy of Management Journal, 42 (6), 599-615.

Li, H. and Atuahene-Gima, K., 2001. Product innovation strategy and the performance of new technology ventures in China, Academy of Management Journal, 44, 1123-1134.

Lopez-Gamero, M. D., Molina-Azorin, J. F. and Claver-Cortes, E., 2010. The potential of environmental regulation to change managerial perception, environmental management, competitiveness and financial performance, Journal of Cleaner Production, 18 (10/11), 963-974.

Majumdar, S. K. and Marcus, A. A., 2001. Rules versus discretion: The productivity consequences of flexible regulation, Academy of Management Journal, 44, 170-179.

Maxwell, B., 1996. In Third International Mathematics and Science Study (TIMSS) Technical Report, I: Design and development (Eds, M. O. Martin and D. L. Kelly) Boston College, Chestnut Hill, MA. 
Montabon, F., Sroufe, R. and Narasimhan, R., 2007. An examination of corporate reporting, environmental management practices and firm performance, Journal of Operations Management, 25, 998-1014.

Niesten, E. and Lozano, R., 2015. Making, buying and collaborating for more sustainable production and consumption, Journal of Cleaner Production, 100, 1-3.

Orlitzky, M., Schmidt, F. L. and Rynes, S. L., 2003. Corporate social and financial performance: A meta-analysis, Organization Studies, 24 (3), 403-441.

Ozsomer, A. and Simonin, B. L., 2004. Marketing program standardization: A cross-country exploration, International Journal of Research in Marketing, 21, 397-419.

Partzsch, L., 2009. Smart regulation for water innovation: The case of decentralized rainwater technology, Journal of Cleaner Production, 17 (11), 985-991.

Porter, M. E., 1991. America's green strategy, Scientific American, 264 (4), 168.

Porter, M. E. and van der Linde, C., 1995a. Green and competitive: Ending the stalemate, Harvard Business Review, 73 (5), 120-134.

Porter, M. E. and van der Linde, C., 1995b. Toward a new conception of the environmentcompetitiveness relationship, Journal of Economic Perspectives, 9 (4), 97-118.

Ramanathan, R. and Akanni, A. O., 2015. The moderating effect of operations efficiency on the links between environmental performance and financial performance: The UK evidence, Asian Journal of Innovation and Policy, 4 (1), 76-101.

Ramanathan, R., Black, A., Nath, P. and Muyldermans, L., 2010. Impact of environmental regulations on innovation and performance in the UK industrial sector, Management Decision, 48 (10), 1493-1513.

Rubashkina, Y., Galeotti, M. and Verdolini, E., 2015. Environmental regulation and competitiveness: Empirical evidence on the porter hypothesis from European manufacturing sectors, Energy Policy, 83, 288-300.

Rugman, A. M. and Verbeke, A., 2000. Six cases of corporate strategic responses to environmental regulation, European Management Journal, 18 (4), 377-385.

Sanchez, C. M. and McKinley, W., 1998. Environmental regulatory influence and product innovation: The contingency effects of organizational characteristics, Journal of Engineering Technology Management, 15 (4), 257-278.

Storper, M., Walker, R. and Widess, E., 1981. Performance regulation and industrial location: a case study, Environment and Planning A, 13 (3), 321-338.

Tanaka, S., 2015. Environmental regulations on air pollution in China and their impact on infant mortality, Journal of Health Economics, 42, 90-103.

Teece, D. J., Pisano, G. and Shuen, A., 1997. Dynamic capabilities and strategic management, Strategic Management Journal, 18 (7), 509-533.

Tello, S. F. and Yoon, E., 2008. Examining drivers of sustainable innovation, Journal of International Business Strategy, 8 (3), 164-169.

Triebswetter, U. and Hitchens, D., 2005. The impact of environmental regulation on the competitiveness in the German manufacturing industry: A comparison with other countries in the European Union, Journal of Cleaner Production, 13, 733-745.

Triebswetter, U. and Wackerbauer, J., 2008. Integrated environmental product innovation in the region of Munich and its impact on company competitiveness, Journal of Cleaner Production, 16 (14), 1484-1493.

Visser, R., Jongen, M. and Zwetsloot, G., 2008. Business-driven innovations towards more sustainable chemical products, Journal of Cleaner Production, 16 (1), Supplement 1, S85-S94.

Walker, H., Di Sisto, L. and McBain, D., 2008. Drivers and barriers to environmental supply chain management practices: Lessons from the public and private sectors, Journal of Purchasing \& Supply Management, 14 (1), 69-85. 
Williamson, O. E., 1999. Public and private bureaucracies: A transaction cost economics perspectives, Journal of Law, Economics, and Organization, 15 (1), 306-342.

Wu, Q., He, Q., Duan, Y. and O'Regan, N., 2012. Implementing dynamic capabilities for corporate strategic change towards sustainability, Strategic Change, 21 (5/6), 231247.

Zhang, Y. J. and Wei, Y. M., 2010. An overview of current research on EU ETS: Evidence from its operating mechanism and economic effect, Applied Energy, 87, (6), 18041814.

Zhao, X., Yin, H. and Zhao, Y., 2015. Impact of environmental regulations on the efficiency and $\mathrm{CO}_{2}$ emissions of power plants in China, Applied Energy, 149, 238-247.

Zhu, K., Kraemer, K. and Xu, S., 2003. Electronic business adoption by European firms: A cross-country assessment of the facilitators and inhibitors, European Journal of Information Systems, 12, 251-268.

Zhu, Q., Sarkis, J. and Lai, K., 2007. Green supply chain management: Pressures, practices and performance within the Chinese automobile industry, Journal of Cleaner Production, 15, 1041-1052. 


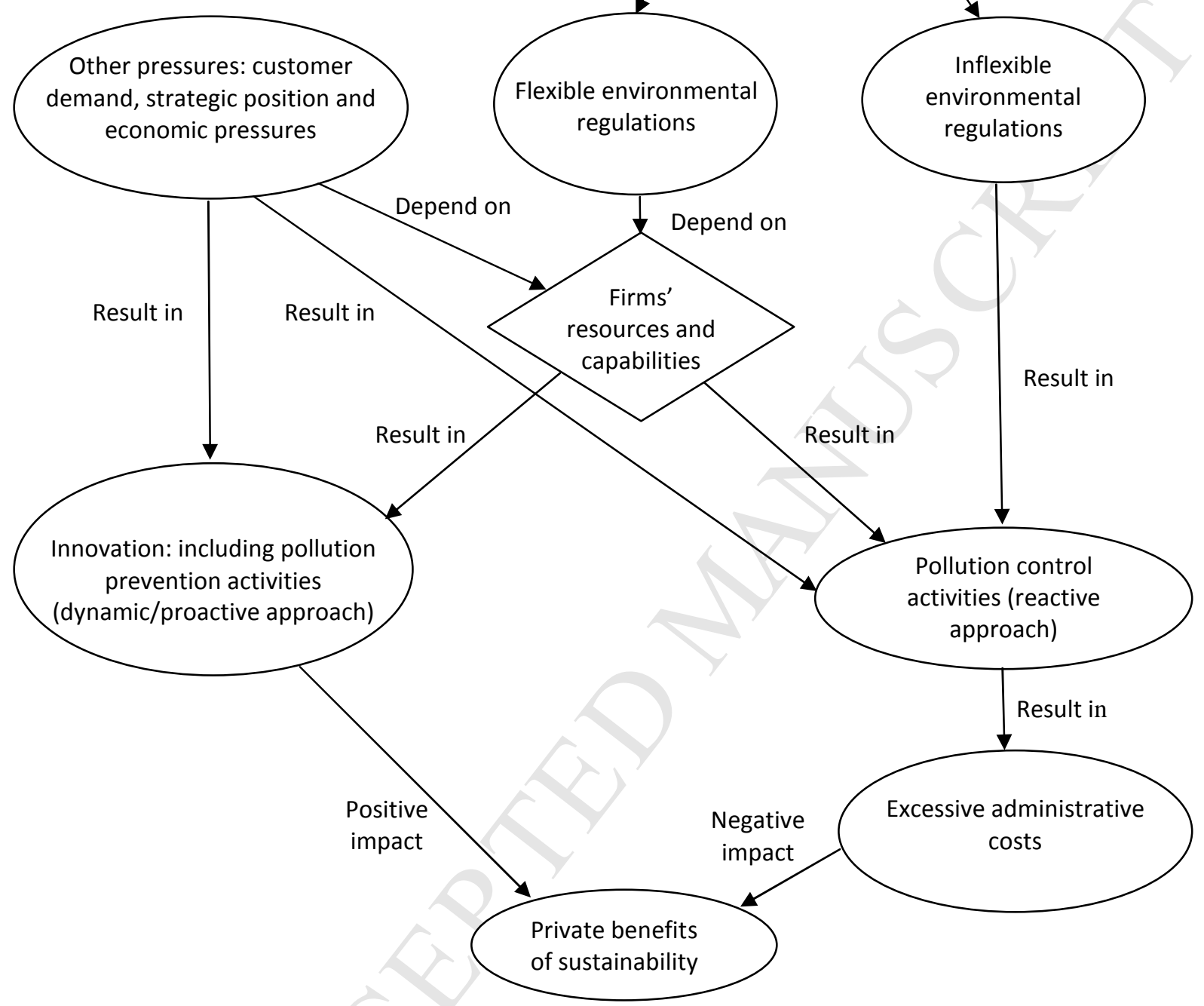

Figure 1. A conceptual framework of environmental regulations, innovation and the private benefits of sustainability. 
Table 1

Initial template based on a priori assumptions.

\section{A priori concepts}

1. Environmental regulations

1.1. Flexible regulation

1.2. Inflexible regulation

2. Firms' responses to regulation

2.1. Dynamic mindset

2.2. Reactive action

3. Innovation and investment

3.1. Investment in environmental management practices

3.2. Environmental innovation initiatives

4. Firms' performance

4.1. Financial performance

4.1.1. Positive impact on financial performance

4.1.2. Negative impact on financial performance

4.2. Environmental performance

4.2.1. Positive impact on environmental performance

4.2.2. Negative impact on environmental performance 
Table 2

Final template based on in-depth analysis of transcripts.

\section{Concepts emerged}

1. Environmental regulation

1.1. Flexible environmental regulations

1.1.1. Directory policy and market-based instrument

1.1.2. Pull-through government funding

1.2. Inflexible environmental regulations

1.2.1. Sudden regulations

1.2.2. Ambiguous regulations

1.2.3. Complexity due to number of regulations

1.2.4. Complicated regulations

1.2.5. Regulations focus on the process

1.2.6. Rigid command-and-control regulations

2. Other pressures: customer demand, strategic position and economic pressures

2.1. Customer demand

2.2. Economic pressures

2.3. Strategic position

3. Firms' resources and capabilities

3.1. Environmental management in organisational structure

3.2. Firms' ability to cope with standards or set the higher standards

3.3. Firms being environmentally conscious

3.4. Tangible and intangible resources

4. Firms' responses to regulations

4.1. Innovation: including pollution-prevention activities (dynamic proactive activities)

4.1.1. Adoption of environmental management practices

4.1.2. Environmental innovation initiatives

4.1.3. Proactive own voluntary environmental initiatives

4.2. Pollution control activities (reactive)

4.2.1. Comply with regulations

4.2.2. Resistance to regulation or transfer pressure to others

5. Excessive administrative costs

6. Environmental performance

6.1. Positive impact on environmental performance

6.2. Negative impact on environmental performance

7. Financial performance

7.1. Positive impact on financial performance

7.2. Negative impact on financial performance 


\section{Appendix A. Interview questions}

1. What are the environmental regulations that your organisation has been subjected to?

2. Can you classify them as (1) direct regulations (that specify some pollution limits) or those that provide economic incentives/disincentives, (2) stipulate environmental standards vs. specify technologies, and (3) encourage integration vs. end-of-pipe?

3. Do you take your decisions on environmental sustainability on the basis of these regulations? What has been the role of environmental regulations (in the UK/China and in other countries) in the adoption of this strategy?

4. Has compliance with environmental regulations produced significant costs for the company which would not have been suffered had the regulations not been in place?

5. What other factors drive your interest in environmental sustainability - voluntary initiatives, economic pressures, stakeholder pressures, etc.?

6. Please outline some voluntary initiatives that you developed to be a leader in environmental sustainability.

7. Can you list the stakeholders that put pressure on you in improving your performance on environmental sustainability?

8. Please list some of the environmental innovations/environmentally friendly activities that you have been involved in (recycling, remanufacturing, using materials internally, waste reduction, energy conservation, outsourcing risk, rewards, supplier selection, environmental awards/recognition, integration with corporate policies, environmental mission, EMS, ecodesign, LCA, DfE, employee programmes, environmental risk analysis, etc.)

9. Can you describe in more detail how some of the specific environmentally focused process innovations that have been implemented work?

10. Have you developed innovative products/processes/patents (not directly relating to environment)? How are these innovations driven by the environmental sustainability agenda?

11. Have you been measuring your environmental achievements - in terms of energy conservation, recycling, waste reduction, savings, etc.?

12. Have you received any important environmental certifications (e.g. ISO 14001)?

13. Have you received any important environmental awards?

14. In terms of its overall performance, is your company registering good sales growth/increase in market share? Have you diversified your product portfolio? Have you reached new geographical markets? Have you introduced new products in the market?

15. What has been the economic impact of the company's improving environmental performance? Please make reference to direct and indirect costs and benefits of the various initiatives undertaken. 
Appendix B. Details of companies chosen for case studies (within-case analysis)






\begin{tabular}{|c|c|c|c|c|c|c|c|c|c|}
\hline CHXIN Co. & Pharmaceutical & $>£ 10 \mathrm{~m}$ & $50-250$ & $>20$ & China & 4 & $\begin{array}{l}\text { CEO; Operation } \\
\text { director; Procurement } \\
\text { director; Sales } \\
\text { director }\end{array}$ & $\begin{array}{l}\text { Strategic; } \\
\text { Senior/middle }\end{array}$ & $\begin{array}{l}\text { Company website, } \\
\text { internal newsletters, } \\
\text { governmental agency } \\
\text { announcements }\end{array}$ \\
\hline KLUN Co. & Pharmaceutical & $>£ 10 \mathrm{~m}$ & $>1,000$ & $>15$ & China & 2 & $\begin{array}{l}\text { Director of safety and } \\
\text { environment } \\
\text { protection } \\
\text { department; } \\
\text { Production line } \\
\text { manager }\end{array}$ & Senior/middle & $\begin{array}{l}\text { Company website, } \\
\text { annual reports, } \\
\text { internal newsletters. } \\
\text { Environmental } \\
\text { Protection Agency } \\
\text { announcements }\end{array}$ \\
\hline OIL Co. & Edible oils & $>£ 10 \mathrm{~m}$ & $>1,000$ & 12 & China & 1 & $\begin{array}{l}\text { General manager of } \\
\text { regional operations }\end{array}$ & Strategic & $\begin{array}{l}\text { Company website, } \\
\text { company newsletters, } \\
\text { Environmental } \\
\text { Protection Agency } \\
\text { announcements }\end{array}$ \\
\hline
\end{tabular}




\section{Environmental Regulations, Innovation and Firm Performance: A Revisit of the Porter Hypothesis}

\section{Highlights}

- Relationships between regulations, innovation and firm performance are examined.

- The Porter hypothesis was used to make some broad preliminary assumptions.

- Inflexible regulations force firms to be reactive and adversely affect financial performance.

- Regulations should foster innovation by providing sufficient flexibility to firms. 